\title{
LAS DIFICULTADES DEL SUBTITULADO EN PELÍCULAS RUMANAS POSTCOMUNISTAS
}

\author{
Vlad Radulian \\ Universidad de Alicante \\ vlad_radulian@yahoo.com
}

\section{RESUMEN}

Este artículo plantea una reflexión sobre las dificultades del subtitulado interlingüístico como mecanismo para promover la cultura de un país. El enfoque elegido es el que nos brinda la traductología y da cabida a reflexiones de orden cultural o lingüístico, así como a algunos criterios para una buena traducción del subtitulado. Con esta propuesta se pretende demostrar la importancia de un buen subtitulado para intercambios culturales exitosos.

Palabras clave: subtitulado, teoría de la traducción, teoría de la cultura, cine rumano.

\section{INTRODUCCIÓN}

La comunidad rumana de España es una de las más numerosas. En un intento de dar a conocer la cultura rumana a los españoles, a finales del 2015, en Alicante se presentó el ciclo de cine rumano y se proyectaron seis de las películas rumanas de la época postcomunista más premiadas a nivel internacional.

El cine rumano logró la fama en la década de 2000 con la aparición de películas como La muerte del señor Lăzărescu, de Cristi Puiu (ganador del galardón Un Certain Regard en Cannes 2005), 4 meses, 3 semanas y 2 días, dirigida por Cristian Mungiu (ganador de la Palma de Oro en Cannes 2007) y Madre e hijo (2013), dirigida por Călin Peter Netzer, (que ganó el Oso de Oro en la Berlinale), todas ellas englobadas en el movimiento cinematográfico denominado Noul val românesc (Nueva ola rumana); es decir, el cine rumano tras la denominada edad de oro, sintagma propio del régimen autocrático rumano.

Las características comunes a estas películas son, en lo temático, su compromiso a la hora de enjuiciar el régimen totalitario de Nicolae Ceauşescu y su repercusión en el paso del comunismo a la economía capitalista. Como afirmó Christian Mungiu, "Lo más importante es la honestidad; buscamos un estilo simple, una manera directa de filmar, un cierto tipo de realismo. La vida es nuestra inspiración, no otras películas o libros». 
El principal factor que se debe tener en cuenta a la hora de escoger esta forma de dar a conocer la cultura de un país es la barrera lingüística. Por ello, si se quiere trasvasar la información cultural sin dejar de ofrecer acceso al contenido y contexto lingüístico del original, teniendo en cuenta tanto al público rumano de España, como al público español deseoso de captar rasgos prosódicos del rumano o simplemente defensor de las versiones originales, una opción viable es el subtitulado. La traducción para subtitulado, como cualquier traducción, debe ser totalmente comprensible en el idioma meta a fin de transmitir el mensaje de la mejor forma, por lo que debe estar adaptada a las normas de la lengua y cultura del receptor: «Traducir es enunciar en otra lengua [...] lo que ha sido enunciado en una lengua fuente, conservando las equivalencias semánticas y estilísticas» (García Yebra 1984, pág. 30).

A pesar de que la equivalencia es un concepto que se ha matizado mucho con la evolución de la traductología en las últimas décadas y a pesar del impacto del descriptivismo, funcionalismo y otros paradigmas en el estudio del producto y el proceso de la traducción, la definición de García Yebra sigue teniendo vigencia si contemplamos el plano semántico en su dimensión cultural. En este sentido, el proceso de traducción implica una serie de complicaciones de las que resultan las dificultades del subtitulado de las películas.

Al abordar el campo de la traducción audiovisual, no sólo se habla del subtitulado, sino también del doblaje (la sustitución de la banda de sonido original por una banda de sonido en la lengua meta) y el voice-over que es otra forma del doblaje en la que no se quita completamente la banda de sonido original, sino se baja su volumen y se le superpone una banda de sonido de la lengua meta (Díaz Cintas 2001, págs. 39-41), como procesos de domesticación cultural. Este término, como es sabido, pertenece al desarrollo teórico realizado por Venuti y se refiere a la naturalización de los extranjerismos lingüísticos o culturales que lleva a cabo el traductor en oposición con la extranjerización (foreignizing).

En el caso del ciclo del cine rumano se optó por la modalidad de subtitulado dentro del género de traducción audiovisual.

El subtitulado es un texto escrito que se encuentra en la parte inferior de la pantalla, o en la parte superior en el caso de ofrecerse subtítulos en más de una lengua. También pueden aparecer en el lateral en el caso de las lenguas cuyo sistema de pictogramas requiere una lectura vertical.

El subtitulado existe en tres formas: la forma interlingüística de un idioma a otro, la forma intralingüística, sin cambio de lengua, que se usa generalmente para público con discapacidad auditiva y, por último, la forma bilingüe que se usa en países o regiones con más de un idioma oficial y estos aparecen para satisfacer las necesidades de los grupos de usuarios de cada idioma (Díaz Cintas y Remael 2007, pág. 14). Estos teóricos señalan que la función del subtitulado es la de reproducir el diálogo del hablante y ofrecer al nuevo espectador la misma impresión que le ofreció al espectador original (Díaz Cintas y Remael 2007).

Los subtítulos deben estar sincronizados con la imagen y con los diálogos (reproduciéndolos con exactitud semántica) y, además, permanecer en la pantalla el tiempo suficiente para que el espectador pueda leerlos (Díaz Cintas 2001, pág. 23).

En el caso del subtitulado es muy importante que el mismo cumpla con tres criterios: tener en cuenta al receptor, transmitir el mensaje y ser creíble. En lo que atañe al primer criterio, el traductor debe saber quién será su receptor, puesto que es esencial que éste disponga del tiempo suficiente para lograr leer los subtítulos sin perder la concentración.

El traductor debe decidir, entre otras cosas, como adaptar, omitir o tratar correctamente los elementos culturales. 


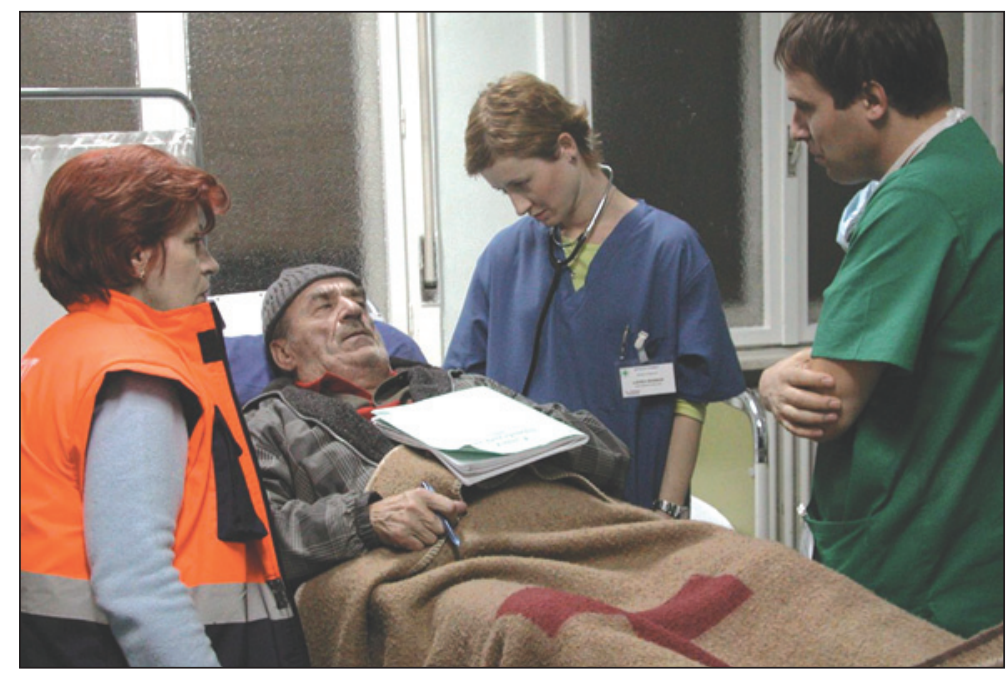

Moartea domnului Lăzărescu (La muerte del señor Lăzărescu, Cristi Puiu, 2005).

Si la traducción logra transmitir el mismo mensaje que el original y crear los mismos efectos estéticos en el receptor meta, entonces el subtitulado es creíble. Para alcanzar este objetivo, una de las condiciones es la corrección lingüística. No se permiten errores de ortografía o gramaticales ni una puntuación que no se adecúe al sistema meta.

En este trabajo, nos proponemos observar elementos relacionados con estos aspectos, tal y como se reflejan en las películas Madre e hijo y 4 meses, 3 semanas y 2 días. Las hemos elegido por tener un subtitulado oficial para su distribución en España. Ambas construyen una historia emotiva sobre la complejidad de las relaciones familiares.

Madre e hijo, escrita y dirigida por Călin Peter Netzer, es un drama que incide en los esfuerzos de una madre para encubrir la responsabilidad de su hijo en un accidente de tráfico saldado con la muerte de un menor. Luminiţa Gheorghiu interpreta a una madre que proviene de las altas capas de la sociedad rumana, que no vacila a la hora de sobornar a los testigos e instigarles a prestar declaraciones falsas en un intento de mantener a su hijo-el conductor responsable del accidente- en libertad.

4 meses, 3 semanas, 2 días es una película dramática de 2007 escrita y dirigida por Cristian Mungiu. La acción ocurre en los últimos años del comunismo en Rumanía y narra los problemas de dos estudiantes que se enfrentan al embarazo no deseado de una de ellas en una época en la que el aborto estaba prohibido por la ley. En la Rumanía de los años ochenta, Otilia y Găbiţa son dos amigas que comparten habitación en una residencia universitaria. Găbiţa está embarazada y contacta con un tal señor Bebe para que le practique un aborto clandestino. Con ese fin, Otilia se encarga de reservar una habitación en un hotel y, posteriormente, se hará pasar por la hermana de Găbiţa para poder acompañar a su amiga durante el proceso, aún más duro y desolador de lo que en un principio habían imaginado.

En el caso de las dos películas analizadas hablamos de un subtitulado interlingüístico; es decir, una traducción de un idioma a otro.

A continuación, analizaremos, por un lado, algunas de las dificultades generales del subtitulado, y por otro lado, las dificultades específicas planteadas por las dos películas arriba mencionadas y derivadas del par de idiomas utilizados (rumano-español). También comentaremos ocasionalmente aspectos culturales que intervienen en el proceso de subtitulación o en el de descodificación por parte del receptor meta. 


\section{DIFICULTADES GENERALES DEL SUBTITULADO}

En el caso de la traducción para subtitulado de contenidos audiovisuales no existe un estándar que la regule. En España existe la norma UNE 153010:2003, Subtitulado para personas sordas y personas con discapacidad auditiva. Subtitulado a través de teletexto, que precisamente regula cómo deben crearse subtítulos para televisión, para cumplir con condiciones impuestas por las características de la percepción humana y de la manera de procesar de la imagen y del texto por nuestro cerebro. Estas normas se aplican también en el caso de la traducción para subtitulado:

- Dado el tamaño de la pantalla, mientras traduce, el traductor está limitado a un máximo de dos líneas, con un interlineado simple;

- Si un subtítulo se presenta ocupando dos líneas, hay que procurar que ambas tengan una longitud similar, pero atendiendo a una serie de reglas para su distribución. Si las dos líneas de un subtítulo no son iguales, la primera tiene que ser más corta que la segunda.

- No se debe separar una palabra silábicamente en dos líneas.

- No se debe separar una unidad de entonación.

- Si la frase consiste en una oración compuesta, se debe intentar separar la frase en cada una de sus oraciones.

- Hay que intentar que la división coincida con las comas y puntos del texto

- La traducción ha de estar centrada (la mayoría de las veces) en la parte inferior de la pantalla.

- Si el subtítulo corresponde a un personaje o narrador, se sitúa en la parte inferior del vídeo, con su texto centrado.

- Si coincide que sobreimpreso en el vídeo en esa zona ya aparece alguna información -por ejemplo, los textos al pie en los informativos-, el subtítulo se puede situar en la zona inmediatamente superior.

- Si el subtítulo corresponde a un efecto de sonido, se sitúa en la parte superior del vídeo, alineado a la derecha.

Según la regla de los seis segundos, el espectador puede leer un máximo de dos líneas de un máximo de cuarenta y dos caracteres en cada línea (Díaz Cintas 2001, pág. 27), por lo que toda traducción ha de adaptarse a estas normas.

Además de estas coerciones técnicas, hay que cumplir también con otros condicionantes de orden sintáctico y gramatical, de modo que la división de la frase se tiene que realizar de manera lógica entre las dos líneas de un subtítulo o entre dos subtítulos, si el final del enunciado no coincide con el del subtítulo.

Los signos de puntuación tienen también un uso específico en el subtitulado. La raya de diálogo, por ejemplo, no se utiliza cuando la réplica de otro personaje aparece en otro subtítulo. Por otra parte, la lectura del texto escrito tiene que dejarle al espectador el tiempo suficiente para seguir la imagen, ofreciéndole solamente el soporte para la comprensión del mensaje.

Por lo tanto, la traducción del subtitulado debe cumplir con requisitos contradictorios. Por un lado, transmitir lo más fielmente posible el contenido sonoro del documento y, por otro lado, no cargar la pantalla y no retener demasiado la atención del espectador, 
ofreciéndole la posibilidad de seguir la imagen. De esta forma, inevitablemente la traducción se convierte en un resumen del texto. Esto es algo normal si lo vemos desde el punto de vista comunicativo. Gran parte de la información nos la ofrece la imagen. El texto sólo debe completar de manera satisfactoria los diálogos. Una película, en tanto que producto artístico, tiene una función estética y una dimensión polisémica que no se tienen que perder por prestar el receptor una atención excesiva a los subtítulos. El espectador tiene que poder seguir los sonidos, la acción, la expresión de la cara de los personajes, los trajes, el paisaje, etc. y, al mismo tiempo, leer los subtítulos.

Obedeciendo la función informativa de estos productos, serán excluidos de la traducción los elementos lingüísticos redundantes, superfluos, como por ejemplo las exclamaciones, los adjetivos o los adverbios acumulativos y las expresiones introductorias. Sin embargo, el traductor tendrá cuidado de no producir vacíos de traducción; es decir, de no dejar réplicas sin equivalencias en la lengua meta y tampoco dejar que se produzca una diferencia de extensión sensible entre el subtítulo y el enunciado oral, lo cual acarrearía la desconfianza del espectador en la calidad y fidelidad de la traducción. La traducción de subtitulado tiene que cumplir con el principio de credibilidad.

A pesar de las coerciones técnicas, la densidad de la información traducida depende del tipo del documento. De esta manera la misma tendrá que ser rigurosamente fiel desde el punto de vista científico en caso de un documental, pero puede obedecer a parámetros traductológicos que contemplen estrategias como la adaptación, la omisión, la compensación, la traducción cero...; es decir, la inserción de texto en lengua origen, en el caso de una película artística. Sin embargo, no debe haber replicas sin traducir, que puedan dejar al espectador la impresión de haber sido privado de información relevante.

Otra dificultad la representan las diferencias existentes entre el discurso oral y el discurso escrito. Muchas veces hay diálogos solapados y esto no se puede reproducir de forma escrita. Además, en el discurso oral hay pausas, repeticiones, marcas dialectológicas, toses, titubeos, falsos comienzos, pero el traductor ha de omitir estos rasgos (para)lingüísticos y convertir la lengua oral en una lengua escrita, sin mermar su esencia y garantizando al mismo tiempo que no pierde su esencia ni infringe las normas que rigen el discurso escrito.

No sólo el modo comunicativo, sino también el canal presenta dificultades. Una de ellas consiste en el soporte del cual se traduce. Lo ideal es que sea un soporte escrito, preferiblemente el guion de la película, junto con una copia de la respectiva película como requisito ineludible. En realidad, las cosas no ocurren siempre así. Se puede dar el caso de que el texto escrito no sea la variante final de la película, de que falte por completo o de que el traductor haga solamente la traducción del texto sin ver la película, lo cual puede dar lugar a traducciones ambiguas y sin sentido.

\section{DIFICULTADES ESPECÍFICAS DEL SUBTITULADO IMPUESTAS POR EL PAR DE IDIOMAS ANALIZADOS, EN ESTE CASO RUMANO-ESPAÑOL}

Estas dificultades están relacionadas sobre todo con aspectos culturales y lingüísticos. Díaz Cintas y Remael (2007: 202) explican que hay nueve estrategias que el traductor puede seguir para resolver el problema de la traducción de las referencias culturales: préstamo, traducción literal, explicación, substitución, transposición, recreación léxica, compensación, omisión y adición. 
El traductor puede tomar prestado un término del idioma original si le resulta imposible traducirlo. Esto ocurre en el caso de los nombres propios, términos gastronómicos, nombres de marcas, etc. Aunque el espectador español no conozca el significado de un término, la mejor solución es a veces trasladar el término del idioma original cuando no existe un equivalente en español. Otra solución es ofrecer un hiperónimo dentro de un mismo campo semántico, o en otras palabras, generalizar el término. Por ejemplo, utilizar comida en vez del tipo de comida.

Otras de las opciones al alcance del traductor son la omisión y la adición. La omisión no solo permite al espectador tener más tiempo para leer los subtítulos, sino también es una modalidad del traductor para mantener la claridad de la lengua.

Ejemplo: 4 meses, 3 semanas y 2 días: «¿Sabes dónde podría conseguir Kent?, porque me hace mucha falta». En este caso, al ser la marca de cigarrillos bastante conocida, no hace falta explicar que se trata de tabaco, pues el espectador español entenderá sin dificultad de qué se trata, aunque no entienda todavía, en ese momento de la película, que el paquete de Kent obtenido del estraperlista sirve para sobornar.

La adición es una buena solución para explicar una referencia cultural. Claro que la adición depende del espacio disponible en el respectivo rótulo. Por ejemplo, si en la película aparece un personaje famoso para el espectador rumano, pero desconocido para el espectador español, el traductor tiene la opción de añadir un cargo u otro elemento que identifique/ defina a ese personaje. Lo mismo ocurre cuando aparece una marca de algún producto local que para el espectador rumano es bastante conocida, pero para el espectador español resulta completamente desconocida.

En 4 meses, 3 semanas y 2 días uno de los personajes va a la habitación del estraperlista en la residencia de estudiantes para comprar cigarrillos y jabón y los pide según el nombre de sus marcas. Para que el espectador español entienda qué está exactamente comprando el personaje, el subtítulo tendría que aparecer así: «Dame entonces un paquete de Assos y un jabón Lux».

A pesar de que en España se conozca la marca de jabones Lux, creemos que es necesario que el traductor añada la palabra jabón antes de la marca Lux para que el espectador español entienda que no se trata de otra marca de cigarrillos en el contexto de Kent y Assos, sino de otro producto que, en la Rumanía de los ochenta, representaba también una mercancía susceptible de sobornos debido a su escasez en el mercado oficial.

Al hablar de dificultades específicas del subtitulado, una mención especial merecen las normas lingüísticas que juegan un papel esencial en la determinación de diferencias entre la lengua hablada (el original) y la lengua escrita (la traducción). No hablamos como escribimos. Esto es cierto también en el caso del par español-rumano. Puede tratarse de diferencias en el vocabulario, en los tiempos verbales y en la construcción de las frases. Además de las diferencias de registro que puedan surgir, hablando cometemos más errores gramaticales, porque no tenemos el mismo tiempo para pensar en lo que queremos decir, que en un discurso escrito. En todo caso, el discurso cinematográfico es sólo parcialmente una imitación de la lengua hablada, ya que en él intervienen la sensibilidad del guionista, su conocimiento del mundo, su idiosincrasia entre otros, al ser, al fin y al cabo, un texto de ficción.

El subtitulado, sin embargo, pertenece a la lengua escrita, y aunque reproduce una lengua hablada, debe estar gramaticalmente correcto y libre de indicios de la lengua hablada. Por ello, se omiten totalmente las interjecciones, las muletillas e imperativos. 
Otro factor importante es la diferencia entre el público receptor en lengua fuente y meta así como entre sus respectivas culturas. En general, el traductor de obras de ficción tiene que decidir qué quiere adaptar, omitir o reproducir directamente del original. En el caso del subtitulado, el traductor está sometido a mayores limitaciones, puesto que ha de obedecer reglas lingüísticas y estilísticas, así como rigores impuestos por las reglas técnicas del subtitulado. De acuerdo con Díaz Cintas (2001: 126), se puede llamar subtitulado exitoso aquel que ofrece al espectador la impresión de que no ha perdido nada en la traducción.

Para superar la dificultad causada por las diferencias entre el discurso oral y el discurso escrito el traductor puede recurrir a varias estrategias. Una de ellas es la estrategia de la reducción de diálogo que contempla dos modalidades denominadas reducción parcial y reducción total (Díaz Cintas, 2001: 124). Ambas modalidades pueden ser empleadas a lo largo de la misma película, como se observa en los dos largometrajes rumanos que analizamos aquí.

La reducción parcial consta de la condensación y la concisión de las partes del discurso original sin relevancia y que no influyen en la comprensión del mensaje por parte del espectador. Por consiguiente, se resume el enunciado en pocas palabras, que no ocupan mucho espacio, utilizándose sinónimos más cortos o construcciones equivalentes a las palabras originales. En cuanto a la reducción total, se trata de la eliminación completa de frases y palabras redundantes, además de todo aquello que no tenga una relevancia directa para la comprensión. Se recurre a esta modalidad en el caso del diálogo solapado, en el que el traductor decide qué omitir y qué no, según su importancia discursiva. Por ejemplo, los elementos susceptibles de pertenecer a esta categoría son las interjecciones y las expresiones vacilantes. Sin embargo, también cabe mencionar que en la traducción no existe una única opción y estas estrategias son sólo posibles soluciones a algunos de los retos a los que se enfrenta el traductor.

Como resumen a todo lo dicho anteriormente, podríamos afirmar que, en el caso del subtitulado, el traductor tiene que traducir una conversación oral de una cultura a una conversación escrita de otra cultura, y cumplir con las coerciones técnicas del subtitulado. Resulta complicado, no obstante, definir, desde el enfoque que nos brindan la traductología, las teorías lingüísticas y culturales, qué se entiende por una buena traducción de subtitulado, puesto que intervienen condiciones específicas y lo que puede ser óptimo desde el punto de vista de la lingüística, puede resultar inaceptable para la traductología. He aquí el dilema y también el reto del traductor de subtitulado.

\section{BIBLIOGRAFÍA}

DÍAZ CINTAS, Jorge, La traducción audiovisual: El subtitulado, Salamanca, Ediciones Almar, 2001.

- y REMAEL, Aline, Audiovisual Translation: Subtitling, Manchester, St. Jerome Publishing, 2007.

GARCÍA YEBRA, Valentín: Teoría y práctica de la traducción, $2^{a}$ edición, Madrid, Gredos, 1984. 